\title{
Regimens of Intraperitoneal Chemotherapy for Peritoneal Carcinomatosis from Colorectal Cancer
}

\author{
KOJI MURONO, KAZUSHIGE KAWAI, KEISUKE HATA, SHIGENOBU EMOTO, MANABU KANEKO, \\ KAZUHITO SASAKI, TAKESHI NISHIKAWA, KENSUKE OTANI, TOSHIAKI TANAKA and HIROAKI NOZAWA \\ Division of Surgical Oncology, Department of Surgery, Faculty of Medicine, the University of Tokyo, Tokyo, Japan
}

\begin{abstract}
Although systemic chemotherapy has been improved, peritoneal carcinomatosis remains a factor of poor prognosis in patients with colorectal cancer. In order to achieve a higher drug concentration in the peritoneal cavity, intraperitoneal chemotherapy has been performed. However, the optimal regimen for intraperitoneal chemotherapy has not been determined. In this review of intraperitoneal chemotherapy for colorectal cancer, we summarize regimens of hyperthermic intraperitoneal chemotherapy (HIPEC) and other intraperitoneal chemotherapy modalities, such as early postoperative intraperitoneal chemotherapy (EPIC) and sequential postoperative intraperitoneal chemotherapy (SPIC). Mitomycin C and oxaliplatin are the most common chemotherapeutic agents used for HIPEC. Some combination therapies such as those involving bevacizumab, $\mathrm{H}_{2} \mathrm{O}_{2}$, and amifostine have potential to increase HIPEC efficacy. 5Fluorouracil is used mainly for EPIC and SPIC. Some new agents such as paclitaxel, melphalan, and various nanoparticles have been developed. These novel chemotherapeutic agents may achieve clinical implementation in the future.
\end{abstract}

The frequency of peritoneal carcinomatosis is approximately 7.3-7.9\% in patients with colon cancer at the time of primary resection, which is relatively low compared to other sites of

This article is freely accessible online.

Correspondence to: Koji Murono, MD, Ph.D., Division of Surgical Oncology, Department of Surgery, Faculty of Medicine, the University of Tokyo, 7-3-1 Hongo, Bunkyo-ku, Tokyo 113-8655, Japan. Tel: +81 358008653, Fax: +81 338116822, e-mail: MURONOK-SUR@h.u-tokyo.ac.jp

Key Words: Colorectal cancer, peritoneal carcinomatosis, intraperitoneal chemotherapy, paclitaxel, review. metastasis such as lung and liver (1). However, it is associated with a very poor prognosis, with a median survival of 6 months in untreated cases $(1,2)$. Although overall survival for treatment with systemic chemotherapy has improved, peritoneal carcinomatosis remains a factor of poor prognosis $(3,4)$.

In 1978, the intraperitoneal administration of chemotherapeutic agents was first described as a method to achieve higher drug concentration in the peritoneal cavity than by intravenous chemotherapy (5). Subsequently, the efficacy of intraperitoneal chemotherapy has been demonstrated for ovarian, gastric, and colorectal cancer (6, 7). In regard to colorectal cancer, Sugarbaker et al. stated that cytoreductive surgery (CRS) and intraperitoneal chemotherapy may potentially increase long-term survival $(8,9)$. After hyperthermic intraperitoneal chemotherapy (HIPEC) was introduced (10), this procedure has become widely implemented in clinical practice. One randomized controlled trial revealed a significant efficacy of CRS and HIPEC $(11,12)$.

However, due to the high morbidity (20-50\%) and mortality (1-6\%) of both CRS and HIPEC (11, 13-15), it is only performed in a limited number of Institutions. Moreover, the efficacy of CRS and HIPEC is limited in patients with highly advanced peritoneal carcinomatosis (16). The development of optimized intraperitoneal chemotherapy regimens may be important to reduce morbidity and mortality, and to improve the effectiveness in highly advanced cases.

In this review, we summarize the current status of intraperitoneal chemotherapy for colorectal cancer focusing on the treatment regimens.

\section{HIPEC}

The regimens of intraperitoneal chemotherapy consist of HIPEC, early postoperative intraperitoneal chemotherapy (EPIC), and sequential postoperative intraperitoneal 
chemotherapy (SPIC). HIPEC is the most common procedure for intraperitoneal chemotherapy. The temperature of the chemotherapeutic agent is maintained at $42-43^{\circ} \mathrm{C}$ to achieve a high drug concentration in the tumor tissue (17). Hyperthermic chemotherapy has been found to increase the concentration and efficacy of doxorubicin in animal models $(18,19)$. This synergistic effect was also demonstrated for mitomycin C (MMC), cisplatin, and oxaliplatin $(17,20,21)$.

Chemotherapeutic agents for HIPEC. There are over 50 studies regarding the treatment of colorectal cancer with HIPEC. The major studies analyzing more than 100 patients are listed in Table I (11-13, 22-38). MMC and oxaliplatin are the most common chemotherapeutic agents used for HIPEC. There have been multiple retrospective studies examining the efficacy of MMC and oxaliplatin for HIPEC treatment. Leung et al. demonstrated that patients treated with HIPEC using oxaliplatin had better prognoses than those receiving MMC-based HIPEC (median survival: 56 vs. 26 months, respectively) (39). Conversely, Prada-Villaverde et al. reported that HIPEC with MMC may be superior to oxaliplatin-based HIPEC when patients have favorable histology or a low burden of peritoneal carcinomatosis (median survival: 54.3 vs. 30.4 months, respectively) (40). In regards to morbidity, despite the frequency of thrombocytopenia being slightly higher in patients receiving oxaliplatin-based HIPEC (41), the mean operative time, mean hospital stay, and the rate of grade $3 / 4$ morbidities according to Common Terminology Criteria for Adverse Events v3.0 were not significantly different between HIPEC treatments using MMC/doxorubicin or oxaliplatin (42). At present there exists no prospective study that compares these two HIPEC regimens. Randomized controlled trials are necessary to standardize these chemotherapeutic regimens.

Irinotecan or cisplatin is sometimes administered in combination with MMC as shown in Table I. Quenet et al. attempted to demonstrate the effect of adding irinotecan to the treatment regimen of patients receiving HIPEC using oxaliplatin (26). However, the overall survival was not significantly different between treatment groups with and without the addition of irinotecan. A phase I study of HIPEC with MMC and irinotecan has been initiated (43). Some combination therapies may become a standard HIPEC regimen in the future.

Agents with potential to increase HIPEC efficacy. Bevacizumab, which targets vascular endothelial growth factor, may increase the efficacy of chemotherapy when administered in the perioperative setting. Bevacizumab was shown to increase the intraperitoneal concentration of oxaliplatin in a murine model (44). Ceelen et al. reported that patients receiving HIPEC therapy using either oxaliplatin or MMC, combined with preoperative intravenous bevacizumab, showed a better prognosis than those without bevacizumab (median survival: 39 vs. 22 months, respectively) (34). Chia et al. reported an increase in treatment efficacy with an intraperitoneal administration of MMC, doxorubicin, or cisplatin combined with intraperitoneal bevacizumab (45). However, a rodent model of HIPEC with oxaliplatin found that efficacy was not improved when adding intraperitoneal bevacizumab (46). Moreover, in a retrospective study, the postoperative complication rate in patients treated by HIPEC in combination with bevacizumab was higher than in patients treated by HIPEC only (major morbidity: $33.8 \%$ vs. $18.6 \%$, respectively) (47). In particular, the frequency of intraabdominal abscess was significantly higher in the group using bevacizumab compared to the group not using bevacizumab ( $13.8 \%$ vs. $2.9 \%$, respectively).

MMC in combination with $\mathrm{H}_{2} \mathrm{O}_{2}$ has been shown to increase HIPEC efficacy. Harrison et al. demonstrated the safety of this procedure in a phase I trial. $\mathrm{H}_{2} \mathrm{O}_{2}$ was found to increase the concentration of MMC in the peritoneal cavity and reduce the serum concentration of $\mathrm{MMC}$, which may intensify antitumor effects and reduce MMC-related toxicity (48).

Agents with potential to reduce HIPEC-related adverse effects. HIPEC with cisplatin has an associated risk of renal dysfunction during treatment. Bouhadjari et al. investigated the effect of amifostine, which is free radical scavenger, for patients treated with HIPEC using oxaliplatin (49). Thirtyone patients receiving amifostine had a lower risk for renal dysfunction (which is defined as a creatinine clearance rate lower than $30 \mathrm{ml} / \mathrm{min}$ ), compared to 21 patients not receiving amifostine (13\% vs. $33 \%$, respectively).

\section{Postoperative Intraperitoneal Chemotherapy: EPIC and SPIC}

Primarily, there are two types of regimens for postoperative intraperitoneal chemotherapy. EPIC is usually performed 4-6 days after surgery, while SPIC may continue for several months. A randomized control trial revealed that the prognosis of patients treated with intraperitoneal 5-fluorouracil (5-FU) and leucovorin for 6 months after surgery was better than that of patients receiving systemic chemotherapy (50). As shown in Table II (23, 27, 51-63), 5-FU is used mainly for EPIC and SPIC.

The overall survival with EPIC therapy was superior to that with HIPEC in a murine model (64). However, a clinical study found that the 5-year survival of patients treated using EPIC, as compared to HIPEC, was worse and was associated with a higher rate of digestive fistulas (55). Moreover, the median survival of patients treated with SPIC was worse than HIPEC in a retrospective study with a small sample size (median survival: 23.9 and 36.5 months, respectively) (15). 
Table I. Hyperthermic intraperitoneal chemotherapy (IPC) for colorectal cancer (limited only to studies of more than 100 cases).

\begin{tabular}{|c|c|c|c|}
\hline Author (Ref) & Year & $\mathrm{n}$ & Agent for IPC \\
\hline Pestieau et al. (22) & 2000 & 104 & MMC \\
\hline Verwaal et al. (11) & 2003 & 105 & MMC \\
\hline Glehen et al. (23) & 2004 & 506 & MMC+cisplatin \\
\hline Cavaliere et al. (24) & 2006 & 120 & $\begin{array}{l}\text { MMC+cisplatin } \\
\text { oxaliplatin }\end{array}$ \\
\hline Verwaal et al. (12) & 2008 & 105 & MMC \\
\hline Elias et al. (14) & 2010 & 523 & $\begin{array}{c}\text { MMC } \pm \text { cisplatin } \\
\text { Oxaliplatin } \pm \text { irinotecan }\end{array}$ \\
\hline Chua et al. (25) & 2011 & 294 & MMC \\
\hline Quenet et al. (26) & 2011 & 146 & Oxaliplatin \pm irinotecan \\
\hline Cashin et al. (27) & 2012 & 151 & $\begin{array}{c}\text { MMC } \\
\text { Oxaliplatin+irinotecan }\end{array}$ \\
\hline Passot et al. (28) & 2012 & 120 & $\begin{array}{c}\text { MMC } \pm \text { irinotecan } \\
\text { Oxaliplatin } \pm \text { irinotecan }\end{array}$ \\
\hline Goere et al. (29) & 2013 & 107 & Oxaliplatin \pm irinotecan \\
\hline Yonemura et al. (30) & 2013 & 142 & MMC+cisplatin \\
\hline Kuijpers et al. (31) & 2013 & 660 & MMC \\
\hline Esquivel et al. (32) & 2014 & 1013 & Oxaliplatin or MMC or other \\
\hline Braam et al. (33) & 2014 & 132 & MMC \\
\hline Ceelen et al. (34) & 2014 & 152 & Oxaliplatin or MMC \\
\hline Levine et al. (35) & 2014 & 232 & MMC \\
\hline Faron et al. (36) & 2016 & 173 & Oxaliplatin+irinotecan \\
\hline Froysnes (37) & 2016 & 119 & MMC \\
\hline Maillet et al. (38) & 2016 & 231 & Not described \\
\hline
\end{tabular}

MMC: Mitomycin C.

Table II. Summary of normothermic intraperitoneal chemotherapy (IPC).

\begin{tabular}{|c|c|c|c|c|}
\hline Author (Ref) & Year & $\mathrm{n}$ & Method & Agent for IPC \\
\hline Glehen et al. (23) & 2004 & 506 & $\mathrm{EPIC} \pm \mathrm{HIPEC}$ & $5-\mathrm{FU}$ \\
\hline Kecmanovic et al. (51) & 2005 & 18 & HIPEC+EPIC & $5-\mathrm{FU}$ \\
\hline Da Silva et al. (52) & 2006 & 70 & HIPEC+EPIC & $5-\mathrm{FU} \pm \mathrm{MMC}$ \\
\hline Fuzun et al. (53) & 2006 & 29 & HIPEC+EPIC & $5-\mathrm{FU}$ \\
\hline Bijelic et al. (54) & 2007 & 49 & HIPEC+EPIC & 5-FU \pm MMC \\
\hline Elias et al. (55) & 2007 & 23 & EPIC & 5-FU+MMC \\
\hline Piso et al. (56) & 2007 & 32 & HIPEC+EPIC & 5-FU \\
\hline Yan et al. (57) & 2008 & 50 & HIPEC+EPIC & $5-\mathrm{FU}$ \\
\hline Bretcha-Boix et al. (58) & 2010 & 20 & HIPEC+EPIC & $5-\mathrm{FU}$ \\
\hline Saxena et al. (59) & 2010 & 63 & $\mathrm{EPIC} \pm \mathrm{HIPEC}$ & $5-\mathrm{FU}$ \\
\hline Cashin et al. (60) & 2012 & 57 & SPIC & 5-FU+leucovorin \\
\hline Klaver et al. (61) & 2012 & 24 & $\mathrm{EPIC} \pm \mathrm{HIPEC}$ & $5-\mathrm{FU}$ \\
\hline Chua et al. (62) & 2013 & 75 & HIPEC+EPIC & $5-\mathrm{FU}$ \\
\hline Huang et al. (63) & 2014 & 62 & HIPEC+EPIC & Docetaxel+carboplatin \\
\hline
\end{tabular}

HIPEC: Hyperthermic intraperitoneal chemotherapy, EPIC: early postoperative intraperitoneal chemotherapy, SPIC: sequential postoperative intraperitoneal chemotherapy, MMC: mitomycin C.

Combining EPIC or SPIC with HIPEC. Since there are few data supporting the superiority of either EPIC or SPIC treatment over HIPEC, the combination of postoperative intraperitoneal chemotherapy with HIPEC has been performed in several studies (Table II). Although the combination of
HIPEC with either EPIC or SPIC may improve survival, the frequency of postoperative complications was higher. Moreover, no survival benefit was observed when the combination of HIPEC using MMC and EPIC using 5-FU was compared with the oxaliplatin-based HIPEC alone $(62,65)$. 


\section{Other Therapeutic Agents and Methods for Intraperitoneal Chemotherapy}

Melphalan. Sardi et al. reported the effect of melphalan, an alkylating agent, in second-line intraperitoneal chemotherapy for 25 patients with peritoneal carcinomatosis, who had poor response to CRS/HIPEC treatments using MMC or oxaliplatin (66). There was no postoperative mortality and grade III-IV morbidity was $23 \%$, which is comparable to that with first-line HIPEC. The long-term overall survival was $89 \%, 45 \%$, and $30 \%$ at 1,3 , and 5 years, respectively, which is acceptable for a second-line treatment.

Paclitaxel. The optimal intraperitoneal chemotherapeutic agent is considered to exhibit the property of retaining a high drug concentration in the peritoneal cavity for an extended period of time. Slowly absorbed agents can meet this aim. Since paclitaxel is water insoluble, it requires solubilization in polyoxyethylated castor oil, also called Kolliphor EL. Its large particle size (10-12 nm in diameter) enables high concentrations of agents to remain in the peritoneal cavity for a longer duration (21). Moreover, slow absorption leads to suppression of serum levels of paclitaxel, which is associated with a lower incidence of adverse effects $(7,67)$.

The clinical efficacy of paclitaxel was demonstrated for peritoneal carcinomatosis originating from primary ovarian or gastric cancer $(67,68)$. Although the effect of paclitaxel was only evaluated in an animal model of colorectal cancer, intraperitoneal administration was superior to intravenous administration in terms of the inhibitory effects on peritoneal tumor growth $(69,70)$. Taxane-based systemic chemotherapy failed to demonstrate efficacy in the treatment of colorectal cancer (71).

Pressurized aerosol. Pressurized aerosols, using oxaliplatin, cisplatin, or doxorubicin, are capable of increasing the local concentration of chemotherapeutic agents (72). Since only $10 \%$ of a typical systemic dose is enough to reach a high local concentration, side-effects may be reduced by maintaining a low serum concentration. Although major adverse effects were not reported according to several case series $(73,74)$, the efficacy of this chemotherapeutic regimen has not been demonstrated.

Low-molecular weight heparin. Reviparin, a low-molecular weight heparin, has shown some potential as an intraperitoneal chemotherapeutic agent in an animal study. Pross et al. demonstrated that the intraperitoneal administration of reviparin was able to reduce tumor weight as a dosedependent effect (75). The suppression of tumor growth and metastasis is considered to be caused by a decrease in cell proliferation, cell adhesion, and cell invasion.
Nanoparticles. In an effort to achieve slow absorbtion of therapeutic agents, various nanoparticles have been developed. Nanoparticles are agents of 20-100 nm in molecular diameter which are suitable for absorption into tumor tissue through the enhanced permeability and retention effect (76).

Paclitaxel-loaded copolymer nanoparticles are able to maintain higher agent concentrations in the peritoneal cavity when compared to paclitaxel (77). Docetaxel-loaded biodegradable porous microspheres, 5-FU-loaded micelles, and cisplatin in a thermosensitive chitosan-based hydrogel have also shown an increase in tumor regression effects in a murine model $(78,79)$. For colorectal cancer, these therapeutic agents have only been investigated using animal models.

\section{Adjuvant Intraperitoneal Chemotherapy to prevent Peritoneal Carcinomatosis}

Adjuvant intraperitoneal chemotherapy has been examined for the prevention of peritoneal recurrence (80). Noura et al. reported that intraperitoneal chemotherapy with MMC prevented peritoneal recurrence in patients with colorectal cancer with positive peritoneal lavage cytology (81). Scheithauer et al. also demonstrated the efficacy of early postoperative intraperitoneal chemotherapy using 5-FU and leucovorin for 241 patients with stage III or T4 colon cancer (82). A randomized control trial demonstrated that peritoneal recurrence decreased when administering postoperative intraperitoneal 5-FU chemotherapy in patients with stage II colon cancer (83). However, in this trial the efficacy of adjuvant intraperitoneal chemotherapy was not observed in patients with stage III colon cancer.

HIPEC has also been performed as adjuvant chemotherapy (84). Tentes et al. reported that patients receiving HIPEC with MMC or oxaliplatin had a better prognosis than those receiving EPIC with 5-FU (85). Based on these results, a randomized control trial for HIPEC with oxaliplatin has been initiated for patients with T4 or intra-abdominally perforated colon cancer without distant metastases (86).

\section{Conclusion}

We reviewed the chemotherapeutic agents used in intraperitoneal chemotherapy for colorectal cancer. MMC and oxaliplatin are commonly utilized agents for HIPEC, with 5-FU typically used for both SPIC and EPIC. However, there have been few prospective studies investigating the optimal intraperitoneal chemotherapy regimen. Some drugs, such as bevacizumab, may increase the efficacy of intraperitoneal chemotherapy, while others, such as paclitaxel and nanoparticles, have the potential to be alternative chemotherapeutic agents. Moreover, intraperitoneal chemotherapy may prevent recurrence in patients with a high risk for 
peritoneal carcinomatosis. In the future, it is necessary to develop safe and more effective chemotherapeutic regimens, as well as establish comprehensive criteria for intraperitoneal chemotherapy.

\section{References}

1 Jayne DG, Fook S, Loi C and Seow-Choen F: Peritoneal carcinomatosis from colorectal cancer. Br J Surg 89: 1545-1550, 2002.

2 Stillwell AP, Ho YH and Veitch C: Systematic review of prognostic factors related to overall survival in patients with stage IV colorectal cancer and unresectable metastases. World J Surg 35: 684-692, 2011.

3 Franko J, Shi Q, Goldman CD, Pockaj BA, Nelson GD, Goldberg RM, Pitot HC, Grothey A, Alberts SR and Sargent DJ: Treatment of colorectal peritoneal carcinomatosis with systemic chemotherapy: a pooled analysis of north central cancer treatment group phase III trials N9741 and N9841. J Clin Oncol 30: 263-267, 2012.

4 Franko J, Shi Q, Meyers JP, Maughan TS, Adams RA, Seymour MT, Saltz L, Punt CJ, Koopman M, Tournigand C, Tebbutt NC, Diaz-Rubio E, Souglakos J, Falcone A, Chibaudel B, Heinemann V, Moen J, De Gramont A, Sargent DJ and Grothey A: Prognosis of patients with peritoneal metastatic colorectal cancer given systemic therapy: an analysis of individual patient data from prospective randomised trials from the Analysis and Research in Cancers of the Digestive System (ARCAD) database. Lancet Oncol 17: 1709-1719, 2016.

5 Dedrick RL, Myers CE, Bungay PM and DeVita VT Jr.: Pharmacokinetic rationale for peritoneal drug administration in the treatment of ovarian cancer. Cancer Treat Rep 62: 1-11, 1978 .

6 Alberts DS, Liu PY, Hannigan EV, O'Toole R, Williams SD, Young JA, Franklin EW, Clarke-Pearson DL, Malviya VK and DuBeshter B: Intraperitoneal cisplatin plus intravenous cyclophosphamide versus intravenous cisplatin plus intravenous cyclophosphamide for stage III ovarian cancer. N Engl J Med 335: 1950-1955, 1996

7 Ishigami H, Kitayama J, Kaisaki S, Hidemura A, Kato M, Otani K, Kamei T, Soma D, Miyato H, Yamashita $H$ and Nagawa $H$ : Phase II study of weekly intravenous and intraperitoneal paclitaxel combined with S-1 for advanced gastric cancer with peritoneal metastasis. Ann Oncol 21: 67-70, 2010.

8 Sugarbaker PH, Landy D, Jaffe G and Pascal R: Histologic changes induced by intraperitoneal chemotherapy with 5fluorouracil and mitomycin $\mathrm{C}$ in patients with peritoneal carcinomatosis from cystadenocarcinoma of the colon or appendix. Cancer 65: 1495-1501, 1990.

9 Sugarbaker PH: Peritonectomy procedures. Ann Surg 221: 2942, 1995.

10 Schneebaum S, Arnold MW, Staubus A, Young DC, Dumond D and Martin EW: Intraperitoneal hyperthermic perfusion with mitomycin $\mathrm{C}$ for colorectal cancer with peritoneal metastases. Ann Surg Oncol 3: 44-50, 1996.

11 Verwaal VJ, van Ruth S, de Bree E, van Sloothen GW, van Tinteren H, Boot H and Zoetmulder FA: Randomized trial of cytoreduction and hyperthermic intraperitoneal chemotherapy versus systemic chemotherapy and palliative surgery in patients with peritoneal carcinomatosis of colorectal cancer. J Clin Oncol 21: 3737-3743, 2003.

12 Verwaal VJ, Bruin S, Boot H, van Slooten G and van Tinteren $\mathrm{H}$ : 8-year follow-up of randomized trial: cytoreduction and hyperthermic intraperitoneal chemotherapy versus systemic chemotherapy in patients with peritoneal carcinomatosis of colorectal cancer. Ann Surg Oncol 15: 2426-2432, 2008.

13 Elias D, Gilly F, Boutitie F, Quenet F, Bereder JM, Mansvelt B, Lorimier G, Dube P and Glehen O: Peritoneal colorectal carcinomatosis treated with surgery and perioperative intraperitoneal chemotherapy: retrospective analysis of 523 patients from a multicentric French study. J Clin Oncol 28: 63-68, 2010.

14 Yan TD, Black D, Savady R and Sugarbaker PH: Systematic review on the efficacy of cytoreductive surgery combined with perioperative intraperitoneal chemotherapy for peritoneal carcinomatosis from colorectal carcinoma. J Clin Oncol 24: 4011-4019, 2006

15 Cashin PH, Graf W, Nygren P and Mahteme H: Intraoperative hyperthermic versus postoperative normothermic intraperitoneal chemotherapy for colonic peritoneal carcinomatosis: a casecontrol study. Ann Oncol 23: 647-652, 2012.

16 Goere D, Souadka A, Faron M, Cloutier AS, Viana B, Honore $\mathrm{C}$, Dumont $\mathrm{F}$ and Elias D: Extent of colorectal peritoneal carcinomatosis: attempt to define a threshold above which HIPEC does not offer survival benefit: a comparative study. Ann Surg Oncol 22: 2958-2964, 2015.

17 Jacquet P, Averbach A, Stephens AD, Stuart OA, Chang D and Sugarbaker PH: Heated intraoperative intraperitoneal mitomycin $\mathrm{C}$ and early postoperative intraperitoneal 5fluorouracil: pharmacokinetic studies. Oncology 55: 130-138, 1998.

18 Los G, Smals OA, van Vugt MJ, van der Vlist M, den Engelse L, McVie JG and Pinedo HM: A rationale for carboplatin treatment and abdominal hyperthermia in cancers restricted to the peritoneal cavity. Cancer Res 52: 1252-1258, 1992.

19 Los G, van Vugt MJ and Pinedo HM: Response of peritoneal solid tumours after intraperitoneal chemohyperthermia treatment with cisplatin or carboplatin. Br J Cancer 69: 235241, 1994.

20 Piche N, Leblond FA, Sideris L, Pichette V, Drolet P, Fortier LP, Mitchell A and Dube P: Rationale for heating oxaliplatin for the intraperitoneal treatment of peritoneal carcinomatosis: a study of the effect of heat on intraperitoneal oxaliplatin using a murine model. Ann Surg 254: 138-144, 2011.

21 Emoto S, Sunami E, Yamaguchi H, Ishihara S, Kitayama J and Watanabe T: Drug development for intraperitoneal chemotherapy against peritoneal carcinomatosis from gastrointestinal cancer. Surg Today 44: 2209-2220, 2014.

22 Pestieau SR and Sugarbaker PH: Treatment of primary colon cancer with peritoneal carcinomatosis: comparison of concomitant vs. delayed management. Dis Colon Rectum 43: 1341-1346, 2000.

23 Glehen O, Kwiatkowski F, Sugarbaker PH, Elias D, Levine EA, De Simone M, Barone R, Yonemura Y, Cavaliere F, Quenet F, Gutman M, Tentes AA, Lorimier G, Bernard JL, Bereder JM, Porcheron J, Gomez-Portilla A, Shen P, Deraco M and Rat P: Cytoreductive surgery combined with perioperative intraperitoneal chemotherapy for the management of peritoneal carcinomatosis from colorectal cancer: a multi-institutional study. J Clin Oncol 22: 3284-3292, 2004. 
24 Cavaliere F, Valle M, De Simone M, Deraco M, Rossi CR, Di Filippo F, Verzi S, Giannarelli D, Perri P, Pilati PL, Vaira M, Di Filippo S and Garofalo A: 120 peritoneal carcinomatoses from colorectal cancer treated with peritonectomy and intra-abdominal chemohyperthermia: a S.I.T.I.L.O. multicentric study. In Vivo 20: 747-750, 2006

25 Chua TC, Morris DL, Saxena A, Esquivel J, Liauw W, Doerfer J, Germer CT, Kerscher AG and Pelz JO: Influence of modern systemic therapies as adjunct to cytoreduction and perioperative intraperitoneal chemotherapy for patients with colorectal peritoneal carcinomatosis: a multicenter study. Ann Surg Oncol 18: 1560-1567, 2011.

26 Quenet F, Goere D, Mehta SS, Roca L, Dumont F, Hessissen M, Saint-Aubert B and Elias D: Results of two bi-institutional prospective studies using intraperitoneal oxaliplatin with or without irinotecan during HIPEC after cytoreductive surgery for colorectal carcinomatosis. Ann Surg 254: 294-301, 2011.

27 Cashin PH, Graf W, Nygren P and Mahteme H: Cytoreductive surgery and intraperitoneal chemotherapy for colorectal peritoneal carcinomatosis: prognosis and treatment of recurrences in a cohort study. Eur J Surg Oncol 38: 509-515, 2012.

28 Passot G, Vaudoyer D, Cotte E, You B, Isaac S, Noel Gilly F, Mohamed $\mathrm{F}$ and Glehen $\mathrm{O}$ : Progression following neoadjuvant systemic chemotherapy may not be a contraindication to a curative approach for colorectal carcinomatosis. Ann Surg 256: 125-129, 2012.

29 Goere D, Malka D, Tzanis D, Gava V, Boige V, Eveno C, Maggiori L, Dumont F, Ducreux M and Elias D: Is there a possibility of a cure in patients with colorectal peritoneal carcinomatosis amenable to complete cytoreductive surgery and intraperitoneal chemotherapy? Ann Surg 257: 1065-1071, 2013.

30 Yonemura Y, Canbay E and Ishibashi H: Prognostic factors of peritoneal metastases from colorectal cancer following cytoreductive surgery and perioperative chemotherapy. Scientific World Journal 2013: 978394, 2013.

31 Kuijpers AM, Mirck B, Aalbers AG, Nienhuijs SW, de Hingh IH, Wiezer MJ, van Ramshorst B, van Ginkel RJ, Havenga K, Bremers AJ, de Wilt JH, Te Velde EA and Verwaal VJ: Cytoreduction and HIPEC in the Netherlands: nationwide long-term outcome following the Dutch protocol. Ann Surg Oncol 20: 4224-4230, 2013.

32 Esquivel J, Lowy AM, Markman M, Chua T, Pelz J, Baratti D, Baumgartner JM, Berri R, Bretcha-Boix P, Deraco M, FloresAyala G, Glehen O, Gomez-Portilla A, Gonzalez-Moreno S, Goodman M, Halkia E, Kusamura S, Moller M, Passot G, Pocard M, Salti G, Sardi A, Senthil M, Spilioitis J, Torres-Melero J, Turaga $\mathrm{K}$ and Trout R: The American Society of Peritoneal Surface Malignancies (ASPSM) Multiinstitution Evaluation of the Peritoneal Surface Disease Severity Score (PSDSS) in 1:013 Patients with Colorectal Cancer with Peritoneal Carcinomatosis. Ann Surg Oncol 21: 4195-4201, 2014.

33 Braam HJ, van Oudheusden TR, de Hingh IH, Nienhuijs SW, Boerma D, Wiezer MJ and van Ramshorst B: Patterns of recurrence following complete cytoreductive surgery and hyperthermic intraperitoneal chemotherapy in patients with peritoneal carcinomatosis of colorectal cancer. J Surg Oncol 109: 841-847, 2014.

34 Ceelen W, Van Nieuwenhove Y, Putte DV and Pattyn P: Neoadjuvant chemotherapy with bevacizumab may improve outcome after cytoreduction and hyperthermic intraperitoneal chemoperfusion (HIPEC) for colorectal carcinomatosis. Ann Surg Oncol 21: 3023-3028, 2014.
35 Levine EA, Stewart JH, Shen P, Russell G. B, Loggie BL and Votanopoulos KI: Intraperitoneal chemotherapy for peritoneal surface malignancy: experience with 1:000 patients. J Am Coll Surg 218: 573-585, 2014.

36 Faron M, Macovei R, Goere D, Honore C, Benhaim L and Elias D: Linear Relationship of Peritoneal Cancer Index and Survival in Patients with Peritoneal Metastases from Colorectal Cancer. Ann Surg Oncol 23: 114-119, 2016.

37 Froysnes IS, Larsen SG, Spasojevic M, Dueland S and Flatmark $\mathrm{K}$ : Complete cytoreductive surgery and hyperthermic intraperitoneal chemotherapy for colorectal peritoneal metastasis in Norway: Prognostic factors and oncologic outcome in a national patient cohort. J Surg Oncol 114: 222-227, 2016.

38 Maillet M, Glehen O, Lambert J, Goere D, Pocard M, Msika S, Passot G, Elias D, Eveno C, Sabate JM, Lourenco N, Andre $\mathrm{T}$ and Gornet JM: Early postoperative chemotherapy after complete cytoreduction and hyperthermic intraperitoneal chemotherapy for isolated peritoneal carcinomatosis of colon cancer: a multicenter study. Ann Surg Oncol 23: 863-869, 2016.

39 Leung V, Huo YR, Liauw W and Morris DL: Oxaliplatin versus Mitomycin C for HIPEC in colorectal cancer peritoneal carcinomatosis. Eur J Surg Oncol 43: 144-149, 2017.

40 Prada-Villaverde A, Esquivel J, Lowy AM, Markman M, Chua T, Pelz J, Baratti D, Baumgartner JM, Berri R, Bretcha-Boix P, Deraco M, Flores-Ayala G, Glehen O, Gomez-Portilla A, Gonzalez-Moreno S, Goodman M, Halkia E, Kusamura S, Moller M, Passot G, Pocard M, Salti G, Sardi A, Senthil M, Spiliotis J, Torres-Melero J, Turaga $\mathrm{K}$ and Trout R: The American Society of Peritoneal Surface Malignancies evaluation of HIPEC with Mitomycin C versus Oxaliplatin in 539 patients with colon cancer undergoing a complete cytoreductive surgery. J Surg Oncol 110: 779-785, 2014.

41 Votanopoulos K, Ihemelandu C, Shen P, Stewart J, Russell G, and Levine EA: A comparison of hematologic toxicity profiles after heated intraperitoneal chemotherapy with oxaliplatin and mitomycin C. J Surg Res 179: e133-9, 2013.

42 Glockzin G, von Breitenbuch P, Schlitt HJ and Piso P: Treatment-related morbidity and toxicity of CRS and oxaliplatinbased HIPEC compared to a mitomycin and doxorubicin-based HIPEC protocol in patients with peritoneal carcinomatosis: a matched-pair analysis. J Surg Oncol 107: 574-578, 2013.

43 Cotte E, Passot G, Tod M, Bakrin N, Gilly FN, Steghens A, Mohamed F and Glehen O: Closed abdomen hyperthermic intraperitoneal chemotherapy with irinotecan and mitomycin $\mathrm{C}$ : a phase I study. Ann Surg Oncol 18: 2599-2603, 2011.

44 Gremonprez F, Descamps B, Izmer A, Vanhove C, Vanhaecke F, De Wever $O$ and Ceelen W: Pretreatment with $\operatorname{VEGF(R)-~}$ inhibitors reduces interstitial fluid pressure, increases intraperitoneal chemotherapy drug penetration, and impedes tumor growth in a mouse colorectal carcinomatosis model. Oncotarget 6: 29889-29900, 2015.

45 Chia CS, Glehen O, Bakrin N, Decullier E, You B, Gilly FN and Passot G: Intraperitoneal Vascular Endothelial Growth Factor: A prognostic factor and the potential for intraperitoneal bevacizumab use in peritoneal surface malignancies. Ann Surg Oncol 22: S880-88, 2015.

46 Verhulst J: Effects of bevacizumab and hyperthermia in a rodent model of hyperthermic intraperitoneal chemotherapy (HIPEC). Int J Hyperthermia 29: 62-70, 2013. 
47 Eveno C, Passot G, Goere D, Soyer P, Gayat E, Glehen O, Elias $\mathrm{D}$ and Pocard M: Bevacizumab doubles the early postoperative complication rate after cytoreductive surgery with hyperthermic intraperitoneal chemotherapy (HIPEC) for peritoneal carcinomatosis of colorectal origin. Ann Surg Oncol 21: 1792-1800, 2014.

48 Harrison LE, Tiesi G, Razavi R and Wang CC: A phase I trial of thermal sensitization using induced oxidative stress in the context of HIPEC. Ann Surg Oncol 20: 1843-1850, 2013.

49 Bouhadjari N, Gabato W, Calabrese D, Msika S and Keita H: Hyperthermic intraperitoneal chemotherapy with cisplatin: Amifostine prevents acute severe renal impairment. Eur J Surg Oncol 42: 219-223, 2016.

50 Cashin PH, Mahteme H, Spang N, Syk I, Frodin JE, Torkzad M, Glimelius B and Graf W: Cytoreductive surgery and intraperitoneal chemotherapy versus systemic chemotherapy for colorectal peritoneal metastases: A randomised trial. Eur J Cancer 53: 155-162, 2016.

51 Kecmanovic DM, Pavlov MJ, Ceranic MS, Sepetkovski AV, Kovacevic PA and Stamenkovic AB: Treatment of peritoneal carcinomatosis from colorectal cancer by cytoreductive surgery and hyperthermic perioperative intraperitoneal chemotherapy. Eur J Surg Oncol 31: 147-152, 2005.

52 da Silva RG and Sugarbaker PH: Analysis of prognostic factors in seventy patients having a complete cytoreduction plus perioperative intraperitoneal chemotherapy for carcinomatosis from colorectal cancer. J Am Coll Surg 203: 878-886, 2006.

53 Fuzun M, Sokmen S, Terzi C and Canda AE: Cytoreductive approach to peritoneal carcinomatosis originated from colorectal cancer: Turkish experience. Acta Chir Iugosl 53: 17-21, 2006.

54 Bijelic L, Yan TD and Sugarbaker PH: Failure analysis of recurrent disease following complete cytoreduction and perioperative intraperitoneal chemotherapy in patients with peritoneal carcinomatosis from colorectal cancer. Ann Surg Oncol 14: 2281-2288, 2007.

55 Elias D, Benizri E, Di Pietrantonio D, Menegon P, Malka D and Raynard B: Comparison of two kinds of intraperitoneal chemotherapy following complete cytoreductive surgery of colorectal peritoneal carcinomatosis. Ann Surg Oncol 14: 509-514, 2007.

56 Piso P, Dahlke MH, Ghali N, Iesalnieks I, Loss M, Popp F, von Breitenbuch P, Agha A, Lang SA, Kullmann F and Schlitt HJ: Multimodality treatment of peritoneal carcinomatosis from colorectal cancer: first results of a new German centre for peritoneal surface malignancies. Int J Colorectal Dis 22: 12951300, 2007.

57 Yan TD and Morris DL: Cytoreductive surgery and perioperative intraperitoneal chemotherapy for isolated colorectal peritoneal carcinomatosis: experimental therapy or standard of care? Ann Surg 248: 829-835, 2008.

58 Bretcha-Boix P, Farre-Alegre J, Sureda M, Dussan C, Perez Ruixo JJ and Brugarolas Masllorens A: Cytoreductive surgery and perioperative intraperitoneal chemotherapy in patients with peritoneal carcinomatosis of colonic origin: outcomes after 7 years' experience of a new centre for peritoneal surface malignancies. Clin Transl Oncol 12: 437-442, 2010.

59 Saxena A, Yan TD and Morris DL: A critical evaluation of risk factors for complications after cytoreductive surgery and perioperative intraperitoneal chemotherapy for colorectal peritoneal carcinomatosis. World J Surg 34: 70-78, 2010.
60 Klaver YL, Chua TC, de Hingh IH and Morris DL: Outcomes of elderly patients undergoing cytoreductive surgery and perioperative intraperitoneal chemotherapy for colorectal cancer peritoneal carcinomatosis. J Surg Oncol 105: 113-118, 2012.

61 Chua TC, Liauw W, Zhao J and Morris DL: Comparative analysis of perioperative intraperitoneal chemotherapy regimen in appendiceal and colorectal peritoneal carcinomatosis. Int $\mathrm{J}$ Clin Oncol 18: 439-446, 2013.

62 McConnell YJ, Mack LA, Francis WP, Ho T and Temple WJ: HIPEC + EPIC versus HIPEC-alone: differences in major complications following cytoreduction surgery for peritoneal malignancy. J Surg Oncol 107: 591-596, 2013.

63 Huang CQ, Feng JP, Yang XJ and Li Y: Cytoreductive surgery plus hyperthermic intraperitoneal chemotherapy improves survival of patients with peritoneal carcinomatosis from colorectal cancer: a case-control study from a Chinese center. J Surg Oncol 109: 730-739, 2014.

64 Klaver YL, Hendriks T, Lomme RM, Rutten HJ, Bleichrodt RP and de Hingh, I. H: Intraoperative versus early postoperative intraperitoneal chemotherapy after cytoreduction for colorectal peritoneal carcinomatosis: an experimental study. Ann Surg Oncol 19: S475-482, 2012.

65 Lam JY, McConnell YJ, Rivard JD, Temple WJ and Mack LA: Hyperthermic intraperitoneal chemotherapy + early postoperative intraperitoneal chemotherapy versus hyperthermic intraperitoneal chemotherapy alone: assessment of survival outcomes for colorectal and high-grade appendiceal peritoneal carcinomatosis. Am J Surg 210: 424-430, 2015.

66 Sardi A, Jimenez W, Nieroda C, Sittig M, Shankar S and Gushchin V: Melphalan: a promising agent in patients undergoing cytoreductive surgery and hyperthermic intraperitoneal chemotherapy. Ann Surg Oncol 21: 908-914, 2014.

67 Yamaguchi H, Kitayama J, Ishigami H, Emoto S, Yamashita H and Watanabe T: A phase 2 trial of intravenous and intraperitoneal paclitaxel combined with S-1 for treatment of gastric cancer with macroscopic peritoneal metastasis. Cancer 119: 3354-3358, 2013.

68 Markman M, Rowinsky E, Hakes T, Reichman B, Jones W, Lewis JL, Rubin S, Curtin J, Barakat R and Phillips M: Phase I trial of intraperitoneal taxol: a Gynecoloic Oncology Group study. J Clin Oncol 10: 1485-1491, 1992.

69 Hribaschek A, Meyer F, Schneider-Stock R, Pross M, Ridwelski $\mathrm{K}$ and Lippert $\mathrm{H}$ : Comparison of intraperitoneal with intravenous administration of taxol in experimental peritoneal carcinomatosis. Chemotherapy 53: 410-417, 2007.

70 Bouquet W, Deleye S, Staelens S, De Smet L, Van Damme N, Debergh I, Ceelen WP, De Vos F, Remon JP and Vervaet C: Antitumour efficacy of two paclitaxel formulations for hyperthermic intraperitoneal chemotherapy (HIPEC) in an in vivo rat model. Pharm Res 28: 1653-1660, 2011.

71 Pazdur R, Lassere Y, Soh LT, Ajani JA, Bready B, Soo E, Sugarman S, Patt Y, Abbruzzese JL and Levin B: Phase II trial of docetaxel (Taxotere) in metastatic colorectal carcinoma. Ann Oncol 5: 468-470, 1994.

72 Solass W, Kerb R, Murdter T, Giger-Pabst U, Strumberg D, Tempfer C, Zieren J, Schwab $M$ and Reymond MA: Intraperitoneal chemotherapy of peritoneal carcinomatosis using pressurized aerosol as an alternative to liquid solution: first evidence for efficacy. Ann Surg Oncol 21: 553-539, 2014. 
73 Odendahl K, Solass W, Demtroder C, Giger-Pabst U, Zieren J, Tempfer C, and Reymond MA: Quality of life of patients with end-stage peritoneal metastasis treated with Pressurized IntraPeritoneal Aerosol Chemotherapy (PIPAC). Eur J Surg Oncol 41: 1379-1385, 2015.

74 Robella M, Vaira M and De Simone M: Safety and feasibility of pressurized intraperitoneal aerosol chemotherapy (PIPAC) associated with systemic chemotherapy: an innovative approach to treat peritoneal carcinomatosis. World J Surg Oncol 14: 128, 2016.

75 Pross M, Lippert H, Nestler G, Kuhn R, Langer H, Mantke R and Schulz HU: Effect of low molecular weight heparin on intraabdominal metastasis in a laparoscopic experimental study. Int J Colorectal Dis 19: 143-146, 2004.

76 Matsumura Y and Maeda H: A new concept for macromolecular therapeutics in cancer chemotherapy: mechanism of tumoritropic accumulation of proteins and the antitumor agent smancs. Cancer Res 46: 6387-6392, 1986.

77 Xu S, Fan H, Yin L, Zhang J, Dong A, Deng L and Tang H: Thermosensitive hydrogel system assembled by PTX-loaded copolymer nanoparticles for sustained intraperitoneal chemotherapy of peritoneal carcinomatosis. Eur J Pharm Biopharm 104: 251-259, 2016.

78 Fan R, Wang Y, Han B, Luo Y, Zhou L, Peng X, Wu M, Zheng $\mathrm{Y}$ and Guo G: Docetaxel load biodegradable porous microspheres for the treatment of colorectal peritoneal carcinomatosis. Int J Biol Macromol 69: 100-107, 2014.

79 Yun Q, Wang SS, Xu S, Yang JP, Fan J, Yang LL, Chen Y, Fu $\mathrm{SZ}$ and $\mathrm{Wu} \mathrm{JB}$ : Use of 5-fluorouracil loaded micelles and cisplatin in thermosensitive chitosan hydrogel as an efficient therapy against colorectal peritoneal carcinomatosis. Macromol Biosci 17: 1600262, 2017.

80 Chouillard E, Ata T, De Jonghe B, Maggiori L, Helmy N, Coscas $\mathrm{Y}$ and Outin $\mathrm{H}$ : Staged laparoscopic adjuvant intraperitoneal chemohyperthermia after complete resection for locally advanced colorectal or gastric cancer: a preliminary experience. Surg Endosc 23: 363-369, 2009.

81 Noura S, Ohue M, Shingai T, Kano S, Ohigashi H, Yano M, Ishikawa O, Takenaka A, Murata $\mathrm{K}$ and Kameyama M: Effects of intraperitoneal chemotherapy with mitomycin $\mathrm{C}$ on the prevention of peritoneal recurrence in colorectal cancer patients with positive peritoneal lavage cytology findings. Ann Surg Oncol 18: 396-404, 2011.
82 Scheithauer W, Kornek GV, Marczell A, Karner J, Salem G, Greiner R, Burger D, Stoger F, Ritschel J, Kovats E, Vischer HM, Schneeweiss B and Depisch D: Combined intravenous and intraperitoneal chemotherapy with fluorouracil + leucovorin vs fluorouracil + levamisole for adjuvant therapy of resected colon carcinoma. Br J Cancer 77: 1349-1354, 1998.

83 Vaillant JC, Nordlinger B, Deuffic S, Arnaud JP, Pelissier E, Favre JP, Jaeck D, Fourtanier G, Grandjean JP, Marre P and Letoublon $\mathrm{C}$ : Adjuvant intraperitoneal 5-fluorouracil in high-risk colon cancer: A multicenter phase III trial. Ann Surg 231: 449-456, 2000.

84 Sloothaak DA, Gardenbroek TJ, Crezee J, Bemelman WA, Punt CJ, Buskens CJ and Tanis PJ: Feasibility of adjuvant laparoscopic hyperthermic intraperitoneal chemotherapy in a short stay setting in patients with colorectal cancer at high risk of peritoneal carcinomatosis. Eur J Surg Oncol 40: 1453-1458, 2014.

85 Tentes AA, Spiliotis ID, Korakianitis OS, Vaxevanidou A and Kyziridis D: Adjuvant perioperative intraperitoneal chemotherapy in locally advanced colorectal carcinoma: preliminary results. ISRN Surg 2011: 529876, 2011.

86 Klaver CE, Musters GD, Bemelman WA, Punt CJ, Verwaal VJ, Dijkgraaf MG, Aalbers AG, van der Bilt JD, Boerma D, Bremers AJ, Burger JW, Buskens CJ, Evers P, van Ginkel RJ, van Grevenstein WM, Hemmer PH, de Hingh IH, Lammers LA, van Leeuwen BL, Meijerink WJ, Nienhuijs SW, Pon J, Radema SA, van Ramshorst B, Snaebjornsson P, Tuynman JB, Te Velde EA, Wiezer MJ, de Wilt JH and Tanis PJ: Adjuvant hyperthermic intraperitoneal chemotherapy (HIPEC) in patients with colon cancer at high risk of peritoneal carcinomatosis; the COLOPEC randomized multicentre trial. BMC Cancer 15: 428, 2015.
Received October 15, 2017

Revised November 4, 2017

Accepted November 10, 2017 